\title{
Analysis of Cohesion and Coherence in Two Truths to Live By
}

\author{
Jing Ye \\ Zhejiang Ocean University, Zhoushan, China \\ Xiaoying Liu \\ Zhejiang Ocean University, Zhoushan, China
}

\begin{abstract}
Discourse analysis is an essential branch of linguistics, and cohesion and coherence are the core issues of discourse analysis. However, many scholars carry out discourse analysis from a specific perspective, and few analyze it from multiple levels simultaneously. Besides, the analysis of the speech is relatively few. Therefore, the study of the multi-level analysis of that style is valuable. This paper is divided into three parts. The first part is the introduction of the theoretical background, expounding the academic research of Halliday, a foreign expert, and Hu Zhuanglin, a domestic representative, and the introduction of the discourse Two Truths to Live by. The second part is the main body of this paper, which explains the function and effect of cohesion and coherence theory by analyzing the sentences in selected texts. Finally, it summarizes the research results. It examines the role of cohesion and coherence in expressing the author's intention and highlighting the theme of the work, so as to cultivate the ability of writing papers, speeches, and other writing styles.
\end{abstract}

Index Terms — cohesion and coherence, socio-semiotic level, semantic level, lexical level

\section{INTRODUCTION}

With the development of linguistics, the study of discourse has been paid more and more attention by linguists. Many researchers have begun to explore the deep structure and stylistic meaning of a text through discourse analysis. Since the 1970s, with the further establishment of cognitive and communicative linguistic views as a new linguistic paradigm, discourse analysis has shifted from the focus on structuralism to the study of the semantic and pragmatic functions of language.

In 1976, the most celebrated linguists Halliday and Hasan published Cohesion in English to define cohesion and divide scopes of it, and also described and analyzed the specific ways of cohesion. On the basis of the research achievements of western scholars, domestic scholars have supplemented the shortcomings of cohesion and coherence theory. A leading contemporary linguist Hu Zhuanglin, has made an in-depth study of cohesion and coherence theory and proposed a multi-level model of cohesion. In his book Discourse Cohesion and Coherence (1994), he added intonation and phonetic patterns to cohesion and coherence theory. However, in recent years, there are few research results on the discourse analysis of English speeches, and most researchers tend to analyze them from a particular perspective.

Therefore, my paper will focus on the discourse analysis of English speeches, and the paper will fall into three parts: the first part is theoretical background information, which states the definition and development of cohesion and coherence theory. I will mainly introduce and conclude the theory proposed by Halliday and Hu Zhuanglin. For the second part, I elaborate on three levels, including socio-semiotic level, semantic level, lexical level, to analyze cohesion and coherence theory. The third part is the summary of the research findings and its limitations.

\section{THEORETICAL BACKGROUND}

\section{A. Introduction of Halliday's Theory of Cohesion and Coherence}

In their book, Cohesion in English, Halliday and Hasan first advocate cohesion as the semantic relationship between one component of discourse and other components that play an important role in explaining it, and it also marks the establishment of cohesion theory. Cohesion has texture, which is the mechanism that constitutes a discourse and this texture is composed of various cohesive ties. Cohesion theory presents five cohesive devices compose of reference, substitution, ellipsis, conjunction, and lexical cohesion (Halliday and Hasan, 1976). Besides, they define text is a semantic unit of language in use, and its size does not define it and they also emphasize that the linguistic analysis is not an interpretation of what the text means; it is an explanation of why and how it means what it does (Halliday and Hasan, 1976). Afterwards, in 1985, in another book, Language, Context and Text, Hasan branched out the concept of cohesion and divided it into structural cohesion and non-structural cohesion. The former includes parallel-symmetric structure, theme-rheme structure, and given-new information structure. The latter can be categorized as constituent relation cohesion, which provides for reference, substitution, ellipsis, and lexical cohesion and organic relation cohesion 
involves conjunctives, adjacency pairs, and continuatives. It is noteworthy that constituent relation cohesion can form three relationships about co-referentiality, co-classification, co-extension. Further development of theory is that the authors propose the notion of context of a situation can be interpreted by means of a conceptual framework using the terms field of discourse, tenor of discourse, and mode of discourse. While, the notion of text can be defined as a metafunctional construct: a complex of ideational, interpersonal, and textual meanings.

\section{B. Introduction of Hu Zhuanglin's Approach}

Based on Halliday's theory, Hu (1994) insists that cohesion and coherence of the text must be reflected in every level of language which includes socio-semiotic level which contains context ( situational, discourse, cultural context )and pragmatic knowledge ( speech act and conversational maxims ); semantic level which is composed of transitivity, logical connection and discourse structure; lexical level which includes reference and lexical cohesion; syntactic level which ranges over structural cohesion and the theme-rheme theory; and the last one is phonological level which consisted of intonation, information unit and speech pattern. Most of all, Hu classifies the phonetic system as a cohesive device. In addition, $\mathrm{Hu}$ elaborates on the connotation and importance of transitivity during the discourse analysis. Also, one of the highlights of his presentation is that the interpretation of the theme-rheme theory and information theory.

\section{Introduction of Author and Two Truths to Live By}

Alexander M. Schindler (1925-2000), Chairman of the Union of American Hebrew Congregations (1973-1996), leader of the Reform Movement of American Judaism for more than two decades and a pivotal figure in 20th century Judaism. Rabbi Schindler's papers contain contemporary perspectives on many of the critical social and cultural issues facing American Jewry and American society from the 1960s to the 1990s. This text Two Truths to Live By is an excerpt from his speech at the commencement of the University of South Carolina, and it discusses one of the paradoxes in life: "to hold fast"and "to let go."The author tries to explain the importance of cherishing beauty when it is offered and to let it go when it is inevitable. Thus, "to let go"is as important as "to hold fast"in our lives.

\section{AnAlysis of Cohesion ANd COHEREnCE In Two Truths To Live By}

\section{A. Language Characteristics of Two Truths to Live By}

As a public speech, this article is an important form of oral communication. The full text has 52 sentences, and each sentence has an average length of 17.2 words. The average length of sentences in the speech exceeds the daily conversation---12 words and impromptu speech---14 words (Wang Zuoliang, Ding Yidao, 1987), which shows that the English public address is more formal and closer to the written style. At the same time, this speech is not as complicated as I have a dream statement structure. The sentences in this speech are mostly short and concise, and they are catchy and readable, attracting readers' attention and being accessible for readers to understand.

Judging from the tone of the sentence, most of the sentences in the speech are declarative and imperative sentences, as well as a small number of interrogative sentences. The use of declarative sentences can make the content of the speech appear solemn, affirmative, and more convincing. The use of imperatives can better convey the intent that the speaker wants to express. In this speech, the orator would like to express his advice to graduates. The use of interrogative sentences makes the language appear lively and eases the atmosphere of the address, making the whole speech not so solemn and aggressive. In addition, the multiple uses of rhetorical devices such as the metaphor, parallelism, and allusions in the discourse makes the rhythm beautiful, rhythm, and poetic.

\section{B. Coherence at Socio-semiotic Level}

In Hu Zhuanglin's work Discourse Cohesion and Coherence, Hu (1994) always emphasizes a point: for meaningful and acceptable discourse, its composition at all levels of the language can show a certain degree of cohesion. Therefore, the intention of the speaker to express in the process of communication runs through the entire text and achieves the purpose of interaction. However, in exceptional cases, the connection between linguistic components does not guarantee that the communicative intentions of the discourse always achieve coherence; on the other hand, discourses with less obvious cohesion are sometimes coherent. Therefore, we must grasp the theme and main content of the entire discourse from the perspective of context and pragmatic knowledge. First of all, the term "context"is used more widely and has different connotations. It can refer to the internal environment of the discourse, that is, the "co-text"; it can refer to the surrounding situation when the discourse is generated, the nature of the event, the relationship of the participants, the time, the place, the way, etc., which can be called "situational context"; It can refer to the historical culture and customs of the speech community in which the speaker is located. People who belong to the speech community can generally understand their meaning in the discourse, which can be called "cultural context."All three help to understand the meaning of the text and the intention of communication, so that the text remains coherent.

Example 1: A recent experience re-taught me this truth. (paragraph 4)

Example 2: This is not an easy lesson to learn, especially when we are young. (paragraph 11)

When we read these two sentences, we can translate them into Chinese according to the semantic components and understand the general meaning. But if you dig deeper, what is "this truth"meaning? What is not an easy lesson to learn? 
Actually, if we connect the linguistic context, we can find it easily that "this truth"means "to hold fast"and "to let go"is a difficult lesson to learn.

Example 3: As we emerged from our unit, the sunlight hit me. (paragraph 6)

From these sentences, out of the situational context, we can only understand the superficial meaning of these sentences. But if we're sitting in the auditorium as graduates listening to this lecture, if we're going to put ourselves in the shoes of the speaker as he suffered disease and then illuminated by the sun, as listeners and readers, it is not difficult for us to understand that sunlight here refers to the beautiful things which are as warm as sunshine in life, and it relates to the hope of survival.

\section{Coherence at Semantic Level}

Any text is the product of the utterance of the speaker's consciousness. In order to turn the speaker's consciousness into speech, the integrated consciousness has to undergo a decomposition process. In this section, I focus on transitive systems.

The subjective and objective world to be reflected in people's thoughts is no more than six processes. These six processes do not occur in a vacuum process, and they involve certain entities (participants), time, space, and mode (environmental factors), which is called transitivity. (Halliday, 1985; Hu Zhuanglin, 1989) Firstly, the material process. It's the process of doing something. Physical processes are generally represented by action verbs. It requires the "actor" and the "target" of the action to be embodied by the noun or nominal word. Secondly, mental processes are processes that represent feelings, reactions, and cognitions, etc. Next, the relational process refers to the process of mutual relations between entities, which can be divided into two categories: attribution and identification. These two categories can be further divided into intensive, circumstantial, and possessive types. Fourth, the Behavioral process refers to physiological processes such as laughing, crying, breathing, etc. The behavioral process only needs one participant. Besides, there are verbal process and existential process.

According to Halliday's transitivity theory, I classified and counted the process of the discourse using six processes. The results showed that there were 52 processes involved: 39 material processes, accounting for $75 \%, 8$ relational processes, accounting for $15 \%$, and 5 psychological processes, accounting for $10 \%$. There is no verbal process or existential process. If we answer the question "who does what to whom?", we find that the participants in this discourse are the speaker himself and the potential listeners and readers. The person with the most appearance in the whole article is called "we," followed by "I." This also shows that the theme of this speech relates to everyone in our daily life. The speaker hopes that through this speech, we can act together, learn to cherish the good things in life, but at the same time learn to let go when the good things are no longer. In the process of persuasion, the speaker mentioned "I" many times to convince the audience and readers with his own personal experience. Next is the relationship process, which illustrates the art of life, the relationship between holding fast and letting go. And then there's the mental process. In the lecture, the speaker described his psychological process towards the essence of life, from regretting and sorrowing for not cherishing the beautiful things like everyone else to realizing the real art of life and learning to be grateful for the people and things around him.

On further analysis, I found that of the 39 physical processes, the vast majority were purposeful and mostly non-living. For instance: never be too busy for the wonder and the awe of life. Be reverent before each dawning day. Embrace each hour. Seize each golden minute. (paragraph 9). This expresses the speaker's perception of holding fast and calls on everyone not to ignore the wonder around us. Greet each dawn reverently, hug time, seize every moment.

\section{Coherence at Lexical Level}

\section{Reference}

Referential relations can be divided into deixis and anaphora. Deixis refers directly to the linguistic features of time and space in the context when the segment occurs. Anaphora is a linguistic unit that means a previously mentioned unit or meaning. (Crystal, 1985) Deixis establishes the connection between language and the outside world, but anaphora determines the internal connection of language. As early as 1976, Halliday and Hasan proposed the concept of phoricity. Not only the two concepts of deixis and anaphora are integrated into a system, but also other cohesive devices involving context are included. They argue that phoricity specifically teaches people to retrieve information from one direction or another in order to interpret relevant paragraphs. In the referential system, the two authors first distinguish between exophoric and endophoric. If the anaphoric word exists in the real or imagined world outside the context, it is the exophoric. If it exists inside a text, it is an endophoric. Halliday and Hasan further distinguished two kinds of situations in the exophoric. There is an exophoric that lies in the situational context other than language, called situational exophoric, and there is a common consciousness of the interlocutors, or in the cultural context of the speech community, called homophoric. The endophoric can be divided into anaphora and cataphora. In addition, reference can be classified into personal reference, social reference, place reference, time reference, and discourse reference. Most importantly, personal reference and demonstrative reference are the two most important types of reference.

In this speech, in order to let the students agree with his understanding of the two truths of life, emphasizing the truth in life is to comprehend to hold fast and to let it go, and encouraging people not to lost the original ideal in pursuit of material satisfaction, meanwhile, not to regret for the lost things, the speaker is extensive use of first-person plural deixis "We". "We"is generally classified as inclusiveness and exclusion. The former includes the listener and the latter 
does not. (Wang, 2015)Schindler frequently used the inclusive we in his speech, always connecting himself with graduates, teachers, and parents.

Example 1: we remember a beauty that faded, a love that waned. But we remember with far greater pain that we did not see that beauty when it flowered, that we failed to respond with love when it was tendered.

In this example, the speaker closely associates himself with every audience present here, and he sees himself as one of them. The speaker wants to express meaning: I am an ordinary person like you. I used to ignore the good things in my life and regret it. This reflects the group trend of the speaker, shortens the psychological distance or emotional distance between the speaker and the listener, and resonates to win the audience's understanding and support. If you switch to the second person plural indicator "you", it is like the speaker's preaching, lack of intimacy, widening the distance between the speaker and the public, it is impossible to achieve the effect of persuasion.

Example 2: In order to resolve this paradox, we must seek a wider perspective, viewing our lives as through windows that open on eternity. Once we do that, we realize that though our lives are finite, our deeds on earth weave a timeless pattern.

The speaker wants everyone to horizon their eyes and looks at the issue from a different perspective. If everyone does this, we will understand that, despite the limits of life, our actions are eternal. Here, the inspiration and persuasion of "we" is one of the pragmatic strategies for the success of the speech. In addition, here "we" are not just about the audience, but also about the human.

In addition to the first person plural indicator "We," in this speech, the first person "I" is used in the fourth, fifth and sixth paragraphs of the article. It is not difficult to find out that there is a big reason why the author uses the first person, that is: these three paragraphs describe the personal experience of the speaker. Starting from personal experience, and then making thoughtful advice, not only show the speaker's personal charm and equal and friendly personal attitude, but also convey the personal feelings to the audience, which is widespread and profound. Besides, the audience of the speakers is college graduates, who are open-minded and easy to understand and accept personal opinions.

Also, at the end of the speech, Schindler used a large number of second-person indicators "you."

Example 3: Add love to a house and you have a home. Add righteousness to a city and you have a community. Add truth to a pile of red brick and you have a school.

Here, "you" represent the audience, which strengthens the sense of ownership of the audience. The speaker subjectively reduced speech posture and expressed the respect and high expectations of the corresponding graduates were greatly inspiring. He sincerely hopes that young people will live for love, morality, and truth from this moment, not for material things. Only in this way will human life be filled with infinite hope.

\section{Lexical cohesion}

In addition to reference, there is also a vital cohesive device at the lexical level -- lexical cohesion. Lexical cohesion means that the semantic connection, repetition, substitution or co-occurrence of lexicon of some lexemes in a discourse. That is to say, it is worth highlighting that words in the cohesion are not subject to changes in the situation, such as singular and plural, tense, appearance, and part of speech. These words are slightly different in form, but their underlying meaning remains the same, and they have the ability of textual cohesion.

Next, I want to analyze the lexical cohesion.

The first category is called repetition. In the article, the words we, life, truth, paradox, hold fast, and let go are almost throughout the text and appear repeatedly in the speech. It is not difficult to see that the main purpose of this speech is to say that life is a contradiction, but clearly understand that the truth of life is to cherish and let go. The beauty appeared in the third and fifteenth paragraphs of the article and played a role in echoing it. The speaker wants to tell the audience that true beauty is not the material of nothingness, but the spiritual pursuit. The second category is called general word. In this speech, the general term is not common. There are mainly general words such as truth, paradox, etc. The use of these general words follows the economic principles in communication, making the article more concise and clear, not too cumbersome. At the same time, it must be pointed out that in English speeches, the general term refers to objective things, which is closely related to the Western way of thinking focusing on rationality and objectivity. The third is the categorization. Including the subordinate relationship, the partial overall relationship, the collective relationship and the consistent relationship. It is not very prominent in this speech. I will not add more to it here.

The fourth category is similarity. The similarity here includes both positive and negative aspects, which are synonymity or near-synonymity and antonymity.

Example 4: We remember a beauty that faded, a love that waned.

Example 5: Just the light of the sun, and yet how beautiful it was----how warming, how sparkling, how brilliant!

Example 6: Our flesh may perish, our hands will wither, but that which they create in beauty and goodness and truth lives on for all time to come.

In these three examples, we can find that the bold parts are synonymity or near-synonymity. Synonymous words emphasize the role of the aforementioned words, and avoid the monotony of the words, enrich the content of the speech, make the readers catch up and catch the reader's attention. For example, the faded and waned used in example 4, they all contain the meaning of elapse. The speaker emphasized that most people always remember the things that have passed away. This is actually a meaningless thing. The two near-synonymous words used here are for the latter to write that people do not know how to cherish when the good things exist. In example 5, Schindler used three near-synonyms 
to emphasize the beauty of the sun. It's not hard to find out that the sun here means the beauty of living, and it means cherishing the beauty around us. In example 6, Schindler wrote death in two near-synonymous words, using three near-synonymous words to write the contributions that people made while they were alive. Comparing the two, it is not terrible to say that death is just that the flesh has left the world, but the spirit is always alive. In addition to synonymy, similarity also includes antonymity.

Example 7: The art of living is to know when to hold fast and when to let go. For life is a paradox : it enjoins us to cling to its many gifts even while it ordains their eventual relinquishment. The rabbis of old put it this way: "A man comes to this world with his fist clenched, but when he dies, his hand is open."

In this sentence, "hold fast" and "let go," "his fist clenched" and "his hand is open" are very typical anti-sense, which is the anti-sense to better reflect the life is a paradox. The opening of the article is an unambiguous statement: life is a contradiction, which is a foreshadowing of how to balance contradictions and understand the true meaning of life.

Example: 8: But we remember with far greater pain that we did not see that beauty when it flowered, that we failed to respond with love when it was tendered.

In this example, "flowered" and "was tendered"are opposites. This makes the two parts before and after the sentence have apparent differences and make a comparison. Human beings, always can not see the existing beautiful, but when the beautiful passed away we began to regret not to cherish.

Example 9: Once we do that, we realize that though our lives are finite, our deeds on earth weave a timeless pattern.

Here, finite and timeless are a pair of antonymy words, emphasizing all the more that though life is limited, our contribution to the world will never vanish. Again, tell the audience to let go of the past or the things that must go. The fifth category is the combinatorial collocation. Combination and collocation are most used in discourse cohesion and play a great role. The last paragraph of this speech is typical. It reflects the causal relationship in combination and collocation.

\section{CONCLUSION}

\section{A. Major Findings}

Through the above analysis at the socio-semiotic level and transitivity of semantic level, we can see that: first, the understanding of context is conducive to the understanding of discourse. When we are reading a text or listening to a speech, in order to grasp the main idea of the text faster and better, we need to combine the linguistic context, bring into the situational context, and even need to have the same cultural background knowledge as the author or orator. In this speech of Two Truths to Live By, I found that to understand the main idea of the whole article, the words or sentences in many paragraphs must be combined with the co-text to understand its connotation. It is through this method that the speaker skillfully makes the theme he wants to convey throughout the whole text and keeps the audience and readers in the context of the situation he provides. In speeches, this cohesive device plays a functional role in coherence and makes speeches more convincing.

Second, through the analysis of transitivity at the semantic level, we come to the conclusion that the relationship between process and participants can also reflect the features of discourse. In the Two Truths to Live By, we can easily find that the participants are speakers and listeners, so the tone of the text is formal and serious. The essence of this discourse is an argumentation, which aims to persuade the audience and express to them the understanding of the truth of life. In addition, the speech adopts more than half of the material processes, and most of the material processes are effective, with behaviors and objects, goals and actions. This exactly reflects that the speaker has a full understanding of the truth of life, indicating that as long as people understand the true meaning of life and effort to do, is the highest respect for life. This is very powerful to render the theme of the speech, enhance the appeal, so that the audience and readers have emotional resonance.

Third, the process of the speaker's speech is the process of assigning speech roles to himself and the listener. As the speaker assigns roles to himself, he also assigns roles to the communicative counterpart. In this speech, Schindler frequently uses the first person plural "we" and the first person "I" to shorten the distance with the audience, instead of assuming a lofty position. The speaker uses his own experience to impress the audience and the reader. He expresses the idea that "I am one of you." It is helpful for the listeners to put themselves in the position of thinking about the two truths of life and accepting the speaker's point of view. At the end of the article, the speaker switched to the second person "you", which shows his keen expectation and expectation for graduates. It can be seen that referential style plays an important role in expressing the theme of speech and the meaning of interpersonal relationship. In addition, some other references, to avoid the article jumbled and easy to understand also play a very important role.

Fourth, the role of lexical cohesion in the cohesion of the whole discourse should not be ignored. Lexical cohesion is frequently used in English speech. Through the analysis of the Two Truths to Live by, I found that the similarity in lexical cohesion is mostly used in this article. This is very worth learning when we write English articles. The use of similarity can not only highlight the speaker's point of view, but also avoid the simplicity of vocabulary. Even some synonyms are used in conjunction with a certain rhythm, such as alliteration, end rhyme, to read catchy and to attract the attention of the audience. In addition, lexical repetition is also widely used in speech discourse. Repetition is important to emphasize the subject word and the point the speaker is trying to assert. When we are listening to a speech, 
it helps us to understand the whole speech by catching the words the speaker mentions repeatedly. It is worth emphasizing that vocabulary collocation plays a large part in the whole speech. Correct and beautiful vocabulary collocation, fully reflects the rigor, logic and sound of speech.

In conclusion, cohesive devices play an important role in discourse coherence. For English majors, mastering the correct use of discourse cohesion means is of great help for their future writing, speech and reading.

\section{B. Limitations of the Study}

This study starts from Hu zhuanglin's theory of discourse cohesion and coherence and studies discourse coherence according to existing cohesive devices. Due to my limited theoretical knowledge and practical experience, I failed to study cohesion and coherence theory from more microscopic linguistic perspectives, which is the biggest shortcoming of this study.

\section{Suggestions for Further Study}

This paper is not a perfect work. In this study, Two Truths to Live By fails to be analyzed in great detail at each level. So there are still lots of linguistic points in it which can be studied further and analyzed in more detail. First, at the lexical level, there are many cohesive devices needed to be found and explained, which are really useful in writing, such as lexical collocation, referentiality. Next, Sound pattern is a key point the listeners and readers cannot ignore when they read or listen this discourse, so there is still room in studying sound pattern. Lastly, cohesive devices syntactic level should be taken into consideration so as to get a more objective explanation.

\section{REFERENCES}

[1] Delu Zhang \& Aijie Zhang. (2006). The Cohesion and Coherence of Situational Context and Discourse. Journal of Ocean University of China (social science edition), 1, 44-47.

[2] Halliday, M. A. K. \& R. Hasan. (1976). Cohesion in English. London: Longman.

[3] Halliday, M.A.K. \& Hasan. (1985). Language, Context and Text. Victoria: Deakin University Press.

[4] Hong Zhao \& Zhihong Shao. (2002). A Contrastive Study on the Referential Function of English and Chinese Third Person Pronouns. Foreign Language Teaching and Research (bimonthly), 34, 174-179

[5] Zhuanglin Hu.(1994). Discourse Cohesion and Coherence. Shanghai: Shanghai Foreign Language Education Press.

Jing Ye was born in Lishui, China in 1997. She is a grade four student at Zhejiang Ocean University, China, majoring in English.

Xiaoying Liu was born in Rizhao, China in 1992. She received her MA degree in linguistics from Xiamen University, China in 2018. She is currently an assistant teacher in the School of Foreign Languages, Zhejiang Ocean University, Zhoushan, China. Her research interests include Systemic Functional Linguistics, Discourse Analysis and Psycholinguistics. 